Textos 



\section{Conhecimentos ecológicos \\ indígenas e recursos naturais: a descolonização inacabada}

GONZALO AGUILAR CAVALLO ${ }^{I}$

\section{Introdução}

$\mathrm{E}$ STE TRABALHO tem por objetivo examinar a importância de considerar as contribuições das visões e conhecimentos indígenas para o desenvolvimento sustentável e, em particular, para a gestão e conservação dos recursos naturais que se encontram no meio ambiente. Cabe ressaltar que esta análise não pretende realizar uma defesa da teoria do relativismo cultural.

Nossa proposta consiste em destacar os conhecimentos indígenas tradicionais, particularmente em relação com o uso e a conservação dos recursos naturais, como uma alternativa possível ao desenvolvimento sustentado no crescimento econômico e no consumo sustentável. Desse modo, tais conhecimentos indígenas tradicionais emergiriam como um valioso insumo que permitiria a releitura do princípio do desenvolvimento sustentável.

Em uma primeira parte, examinaremos os novos enfoques libertadores de um colonialismo inacabado através do conhecimento tradicional; e, logo, em uma segunda parte, nos concentraremos na análise do paradigma cognitivo indígena vinculado com a posse de terras, territórios e recursos naturais através das decisões proferidas no sistema interamericano de proteção de direitos humanos.

\section{A mudança de paradigma}

e o conhecimento tradicional

A colonização da América significou a imposição do conhecimento europeu aos povos que habitavam o continente (Eudave, 2016). Castro-Gómez e Grosfoguel (2007, p.20), sustentam que "[l] a superioridad asignada al conocimiento europeo en muchas áreas de la vida fue un aspecto importante de la colonialidad del poder en el sistema-mundo. Los conocimientos subalternos fueron excluidos, omitidos, silenciados e ignorados". Isso ocorreu em todas as áreas, na economia, na religião, na política e também no direito. O conhecimento nativo não foi considerado ou, quando o foi, foi tido como inferior e, portanto, foi desprezado (Vanhulst; Beling, 2013). Com efeito, como afirma Gareis (2005, p.12), "[e]sta pretensión reflejaba la base ideológica de todas las formas de colonialismo, que es la presunta inferioridad del otro". No que se refere a terras, territórios e recursos naturais indígenas, nos dias de hoje não há muita modificação no 
que diz respeito à situação existente há 500 anos, nos amanheceres da colonização europeia do continente americano. Daes é clara ao destacar que

[...] [l]a exploración y colonización de otras regiones por paises de Europa que se inició en el siglo $X V$ condujo rápidamente a la apropiación, por los principales imperios europeos, de las tierras y recursos naturales de los pueblos indigenas. [...] Los pueblos indigenas fueron sucesivamente despojados de sus tierras, su ciencia, sus ideas, su arte y su cultura. (Comisión de Derechos Humanos, 1993, par.18)

Através da colonização, os Estados europeus impuseram uma forma de conhecimento que, ao final, se transformou em hegemônica. Com a Segunda Guerra Mundial, o mundo admitiu o surgimento de uma noção, de base, eurocêntrica, denominada direitos humanos (Gómez, 2001, p.270) (Velasco Criado, 1999). O fundamento geralmente aceito quanto aos direitos humanos se situou na dignidade humana, entendido como um conceito inspirado na cultura europeia. ${ }^{1}$ Esses direitos se transformariam em um padrão axiológico de comportamento, por exemplo, no âmbito da propriedade e da proteção do meio ambiente. Desse modo, os direitos humanos, como uma particular forma de explicar e regular a posição do ser humano dentro de uma sociedade, também resultam de uma importação europeia, o que nos conduz ao tradicional debate entre universalismo e relativismo (Boco; Bulanikian, 2010, p.13; Ferrero Hérnandez, 2016, p.101).

Dentre os conhecimentos alternativos e as formas diversas de compreender o mundo, se encontram os denominados conhecimentos tradicionais indígenas. Em um Relatório de 2001, a Organização Mundial da Propriedade Intelectual (OMPI) definiu o conceito de conhecimento tradicional e realizou uma qualificação quanto ao conceito de conhecimento indígena. Assim, destacou que "conocimientos indigenas' serian los conocimientos tradicionales de los pueblos indigenas. Por consiguiente, los conocimientos indigenas forman parte de la categoría de los conocimientos tradicionales, pero los conocimientos tradicionales no son necesariamente indigenas” (OMPI, 2001, p.23).

Surge, então, a pergunta de que significa a expressão conhecimento tradicional. Os conhecimentos tradicionais incluiriam o que se denomina folclore, mas também o conhecimento tradicional "de plantas y animales en los tratamientos médicos y como alimento, por ejemplo. En tales casos, el análisis pasaría del sector del derecho de autor al de legislación de patentes o al de derechos sobre diversidad biológica" (OMPI, 1999, p.3).

Como poder-se-ia entender o conhecimento indígena tradicional? A expressão poderia ser compreendida como

[...] un cuerpo acumulado de conocimientos y creencias traspasado culturalmente de generación en generación, referente a las relaciones entre organismos vivos (incluyendo bumanos) con el medio ambiente, es un atributo de las sociedades con continuidad histórica en la práctica del uso de recursos, las cuales generalmente no son industriales y son menos avanzadas tecnológicamente. 
En todos los casos, la tradición pasa oralmente entre generaciones y no hay registro escrito de tal conocimiento. (Prieto Acosta, 2004, p.138)

Naturalmente, existe uma relação entre o conhecimento indígena tradicional e a noção de patrimônio no caso dos povos indígenas. De mesmo modo, é possível a associação com a herança cultural indígena ou patrimônio. Os conhecimentos tradicionais indígenas, forjados através da experiência prática e das vivências e observações no decorrer dos séculos de convivência, constituem-se num dos pilares dos usos e manejos que os povos indígenas realizam da nature$\mathrm{za}$, de suas terras e dos recursos naturais.

Em estudo realizado em 1993, a relatora Erica-Irene Daes (Comisión de Derechos Humanos, 1993, par.24) aborda o conceito de patrimônio para compreender a proteção da propriedade cultural e intelectual dos povos indígenas e, também, o patrimônio histórico e natural. Como será ainda discutido mais adiante, Daes refere uma peça-chave no desenvolvimento de postulados contemporâneos do um constitucionalismo da responsabilidade, dentro do qual se pode incluir a noção de "bem viver". Com efeito, Daes afirma que " [e]n realidad, los pueblos indígenas no ven en absoluto su patrimonio como una propiedad -es decir, bienes que tienen un propietario y que se utilizan para obtener beneficios económicos- sino en términos de responsabilidad individual y colectiva" (Comissión de Derechos Humanos, 1993, par.26).

Logo, em seu projeto de princípios e diretrizes para a proteção do patrimônio dos povos indígenas do ano 2000, Daes assinalou que "[e]l patrimonio de los pueblos indigenas tiene un carácter colectivo" (Comisión de Derechos Humanos, 2000, par.13).

$\mathrm{E}$, além do mais, completou que entende como incorporados nesse patrimônio

[...] todos los bienes culturales muebles, definidos en las convenciones pertinentes de la Unesco; todos los tipos de obras literarias y artísticas como música, baile, canciones, ceremonias, simbolos y diseños, narración y poesía; y todas las formas de documentación de los pueblos indigenas o sobve ellos; todo tipo de conocimientos científicos, agricolas, técnicos y ecológicos, incluidas las innovaciones basadas en esos conocimientos, cultigenos, remedios, medicinas y el uso de la flora y de la fauna; restos humanos; bienes culturales inmuebles como lugares sagrados, emplazamientos de valor cultural, natural e histórico y enterramientos. (ibidem, par.13)

Quando falamos de conhecimento indígena tradicional, não só nos referimos aos distintos saberes e sabedorias acumuladas através dos séculos de existência e civilização, como também às formas distintas de ver o mundo, isto é, a visão holística pela qual a existência humana é descoberta pelas comunidades indígenas. Nesse sentido, Acosta (2010, p.14) observa que " [e]l buen vivir aparece como una categoría en la filosofía de vida de las sociedades indigenas ancestrales, que ha perdido terreno por efecto de las prácticas y mensajes de la modernidad occidental". 
$\mathrm{Na}$ América, a presença de comunidades indígenas e tribais tem facilitado a abertura dessa brecha no conhecimento (Mejía Navarrete, 2015). E, nesse ponto, o continente compartilha as características com a África. Por essa razão, é tão importante que os continentes dialoguem quanto às suas experiências práticas nessa temática e, igualmente, por isso é relevante que o mundo intelectual e profissional americano volte seus olhos para o continente africano. A existência de um componente comunitário e eminentemente coletivo no seio da sociedade africana, assim como no seio da sociedade americana explicaria a necessária aproximação que deveria existir na leitura de formas pelas quais se deveria abordar o conhecimento desses direitos. Note-se que no caso africano esse último é intocado, já que o próprio nome do principal instrumento de proteção dos direitos o explicita: Carta Africana sobre os Direitos Humanos e dos Povos (1981).

Uma manifestação relevante desses conhecimentos indígenas tradicionais, no âmbito da efetividade na utilização dos recursos naturais e das diretrizes sobre o desenvolvimento, é constituída pela noção de bem viver. O conceito de bem viver pretende explicitar a ideia de um desenvolvimento integral, inspirada na tradição indígena e que propõe uma mudança de paradigma ante a concepção capitalista de desenvolvimento, e que, como já assinalamos, segundo Houtart (2011), encontra noções similares nas sociedades africanas e asiática. Nesse sentido, Acosta $(2015$, p.301) afirma que o "Buen Vivir, en tanto cultura de la vida, con diversos nombres y variedades, ha sido conocido y practicado en distintos períodos en las diferentes regiones de la Madre Tierra, como podría ser el Ubuntu en África o el Svadeshi, el Swaraj y el Apargrama en la India". Ubuntu, por exemplo, se pode expressar com a máxima "uma pessoa é uma pessoa através de outras pessoas", o que, para os observadores ocidentais poderia parecer uma ideia bastante obscura. Contudo, também

[...] se puede revelar en las siguientes interpretaciones: "uno se convierte en una persona moral en la medida que uno honre las relaciones comunitarias", o "un ser humano vive un modo de vida genninamente bumano en la medida que esa persona aquilata la identidad y la solidaridad con otros seres bumanos", o "un individuo realiza su propia persona respetando el valor de la amistad". (Metz, 2011, p.540)

Cabe destacar que nesse conceito de humanidade se vive através da identidade e da solidariedade com os outros seres. Note-se a simetria com as visões indígenas, nas quais "[l]a cosmovisión y prácticas culturales de estos pueblos han estado intimamente relacionadas con los espacios naturales y se diferencian de las visiones de otros actores que separan lo natural de lo humano" (Barragán Alvarado, 2011).

Em matéria de recursos naturais, se os territórios indígenas são tão ricos em recursos é porque durante séculos eles têm interagido com a natureza de maneira harmoniosa, alcançando um conhecimento que lhes tem permitido levar adiante um uso sustentável de seus recursos (Nakashima; Prott; Bridgewater, 2000). A visão hegemônica do desenvolvimento, do consumo e do crescimento econômico tem anulado esse conhecimento alternativo, não hegemônico, local, 
tradicional (Sousa Santos, 2010). Assim, "a partir de la perspectiva del sistema-mundo, la modernidad es concebida en su articulación con el capitalismo y la colonialidad" (Caba; García, 2014, p.6).

Segundo Sousa Santos (2010), a história de nosso tempo se encontra baseada em um "epistemicídio", i.e., na destruição, iniciada na América há 500 anos, de outros conhecimentos alternativos. De acordo com Caba e García, (2014, p.6), a partir dessa época, "todo el globo se torna el lugar de una sola sociedad, de una sola historia hegemonizada por Europa”.

Poder-se-ia dizer que no caso da América Latina,

[...] [a] partir de estos procesos de epistimicidio - despojos epistémicos intencionales - se han creado unas subjetividades discriminadas, como es el caso de los indigenas a quienes no se les ha reconocido sus saberes ancestrales y han pasado de ser los propietarios nativos de estos territorios a ser poblaciones diferenciales que apenas en las últimas décadas (sic), se les ha reconocido en las Cartas Constitucionales sus derechos humanos. (Correa Muñoz; Saldarriaga Grisales, 2014, p.163)

O resgate e a validade dos conhecimentos alternativos é o que alguns chamam de descolonização epistemológica. Caba e García (2014, p.6) assinalam que por "descolonización epistemológica se entiende entonces un intento que [...] busca la gestación de un pensamiento en diálogo con conocimientos de la periferia que han sido despreciadas y/o silenciadas por la superioridad autoasignada de la cultura europea" (cf. Quijano, 2012). Essa validação do conhecimento alternativo, em particular, do conhecimento indígena tradicional, é, em certa medida, o que a Corte IDH, talvez até sem tal pretensão, tem realizado em torno da posse e das formas de uso ancestral das terras territórios e recursos naturais desses povos (cf. Frias, 2017). Então, cada vez que é imposto um direito aos povos indígenas gestado em uma sociedade com uma visão de mundo eurocêntrica e com uma forma de se inter-relacionar com a natureza e com os recursos naturais distinta de sua forma, também nesse momento se atualiza o colonialismo.

Há aqui o drama do conhecimento alternativo indígena vis-à-vis suas terras, seus territórios e recursos naturais, refletido, em parte, em seu conhecimento ecológico tradicional (Berkes; Colding; Folke, 2000). Hoje em dia seus recursos naturais e territórios são amplamente cobiçados porque são áreas que durante séculos mantiveram equilíbrio e se conservaram graças à cosmovisão indígena, razão pela qual gozam de uma incrível riqueza ambiental (Diretrizes de proteção para os povos indígenas em isolamento e em contato inicial da Região Amazônica, o Grande Chaco e a Região Oriental do Paraguai). Martínez de Bringas (2009, p. 4) sustenta que

[...] [j]unto a ello, y consustancialmente vinculado al valor de la biodiversidad en la que viven y se asientan, es necesario percibir el valor que se deriva de estos territorios en forma de conocimiento tradicional y patrimonio inmaterial indigena, con un valor cultural insondable para estos pueblos. Se trata de prácticas, innovaciones y conocimientos orientados a la conservación y 
utilización sostenible de sus territorios, es decir, a la producción, reproducción $y$ desarrollo de la vida individual y colectiva. Hoy, estos conocimientos tradicionales y estas expresiones de patrimonio tienen un valor inaudito para el capital debido a las posibilidades que otorga su mercantilización.

Então, esse conhecimento indígena tradicional orientado a conservação e uso sustentável dos recursos pode ser uma via alternativa ao desenvolvimento ante aquela fórmula que parece esgotada e que provém da visão hegemônica. Seguindo Berkes (1995), não utilizamos o termo conservação no sentido de preservação, mas no sentido de uso para o benefício humano, sem comprometer os interesses das gerações futuras. Nesse sentido, a lição que nos oferece o conceito de "bem viver" valeria a pena ser aprendida.

\section{Terras, meio ambiente e recursos naturais desde o conhecimento tradicional}

Nesta parte, pretendemos nos concentrar na particular forma de compreensão que detêm os povos indígenas e, portanto, de relacionar-se com o mundo, tendo em vista suas terras, seus territórios, meio ambiente e recursos naturais nele existentes. Nossa análise dessa visão alternativa do mundo se realizará a partir da prática jurisprudencial interamericana. A ênfase será dada não tanto no direito dos povos indígenas à propriedade coletiva de suas terras e recursos naturais e o necessário reconhecimento de seus conhecimentos e culturas tradicionais por trás desse reconhecimento, mas no aporte que esses conhecimentos indígenas tradicionais e suas cosmovisões - já reconhecidos em nível interamericano - podem significar para se alcançar um desenvolvimento sustentável com a proteção da natureza e a conservação dos recursos naturais (Aguilar Cavallo, 2017). Nossa hipótese é que a prática judicial interamericana relativa aos casos sobre os povos indígenas vem permitindo abrir uma brecha em torno dos distintos saberes e formas de enfrentar o mundo, em especial frente ao desafio contemporâneo de desenvolvimento sustentável.

\section{A contribuição dos conbecimentos tradicionais para o desenvolvimento sustentável: bem viver}

O enfoque holístico é representativo de outras formas de conhecimento; de fato, é representativo do conhecimento indígena tradicional, e, portanto, ancestral, muitas vezes considerado como inferior, pelo conhecimento eurocêntrico. Pretendemos examinar se os conhecimentos e visões do mundo que os povos indígenas possuem poderiam constituir uma contribuição para alcançar o objetivo de desenvolvimento sustentável e, em particular, para a gestão e conservação dos bens e recursos naturais que se encontram no meio ambiente. Antes, cabe ter presente o contexto e, quanto a esse, Pinheiro, El-Chichini Poppovic e Khan (1994, p.189) destacam que "en visperas del año 2000, nuestra sobrevivencia está amenazada. El desequilibrio ecológico, los patrones de desarrollo insostenibles y las persistentes divisiones del mundo entre Norte y Sur, entre naciones ricas y pobres, se agravan". 
O desenvolvimento sustentável teve como antecessor o ecodesenvolvimento. O ecodesenvolvimento foi conceitualizado nos anos 1970 por Sachs, o qual postulava que

\begin{abstract}
[...] habia que reorientar la técnica y la ciencia en apoyo al ecodesarrollo en vez de ponerlas al servicio de una lógica de acumulación capitalista creciente, que no sólo alienaba al propio ser humano, sino que, también, destruía la naturaleza y envenenaba el ambiente" $e$, portanto, se tratava de desejar um desenvolvimento "socialmente deseable, económicamente viable, y ecológicamente prudente. (apud Estenssoro, 2015, p.89)
\end{abstract}

Logo, nos anos 1980 aparece no contexto das Nações Unidas o conceito de desenvolvimento sustentável. Com efeito, esse termo foi alcunhado, com grande êxito posterior, no denominado Relatório Brundtland de 1987. O referido Relatório define o desenvolvimento sustentável como "el desarrollo que satisface las necesidades de la generación presente sin comprometer la capacidad de las generaciones futuras para satisfacer sus propias necesidades" (Comisión Mundial sobre el Medio Ambiente y el Desarrollo, 1987, par. l e 9) (Alonso Hierro; Martin Fernández, 2013, p. 1135).

O ecodesenvolvimento e o desenvolvimento sustentável são objetos de crítica pelos defensores do reconhecimento dos conhecimentos alternativos, já que se alega que os primeiros são manifestações da cultura dominante e do conhecimento eurocêntrico. Sem dúvidas, pretendemos propor que o desenvolvimento sustentável e o conhecimento indígena tradicional têm pontos de encontro que permitiriam o melhor proveito de ambos os objetivos que parecem comuns, tais como a conservação da biodiversidade e da diversidade cultural, $\mathrm{o}$ equilíbrio ecológico e a proteção do patrimônio ambiental.

Por uma parte, sustentamos que um dos pontos de união dos pontos mais relevantes entre o desenvolvimento sustentável e os direitos humanos é que ambas as noções se revelam portadoras do conceito de justiça. A justiça é um conceito central de desenvolvimento sustentável, tanto desde a perspectiva de justiça social como da de justiça ambiental e sua específica manifestação da equidade intergeracional. Esses elementos de justiça confluem sem dúvidas nos direitos humanos - direito humano ao meio ambiente saudável e direito humano ao desenvolvimento - convertendo-se em peças-chave da luta contra a desigualdade (Gros Espiell, 1987, p.165). Desse modo, segundo Flores Rentería (2011, p.45) "[l]o injusto es lo inhumano, que existan comunidades e individuos marginados, sumergidos en la pobreza y la ignorancia y, por si ello fuera poco, que se les haga creer que son libres e iguales a sus gobernantes y a los ricos que los oprimen".

Nesse contexto o desenvolvimento sustentável não significa, pois, um bem-estar baseado no mero consumo de bem, mas sim um bem-estar do indivíduo e da sociedade em relação com o entorno, no sentido amplo da palavra, isto é, equilíbrio ecológico e hábitat em harmonia com a natureza. O desenvolvimento centra-se principalmente "en la riqueza de las vidas humanas y no solo en 
la riqueza de las economias" (Informe sobre Desarrollo Humano, 2015). Nesse sentido, precisamente, "[l] a sostenibilidad no es solo, ni en primera instancia, un tema ambiental, [...] se trata, sobre todo, de la forma en que elegimos vivir nuestra vida" (Informe sobre Desarrollo Humano, 2011). Em outras palavras, alude a uma matriz civilizatória e a um modelo de desenvolvimento que estaria representado pelo bem viver (Estermann, 2010). Assim, reconhecendo-se que o desenvolvimento que persegue o direito de mesmo nome é um desenvolvimento sustentável, coincidiria-se com Piovesan (2014a, p.210) no sentido de que "el derecho al desarrollo contempla, asi, tres dimensiones centrales: (a) justicia social; (b) participación y accountability; y (c) cooperación internacional".

O direito ao desenvolvimento tem sido, assim mesmo, reconhecido pela jurisprudência internacional e decisões de órgão quase-jurisdicionais de proteção dos direitos humanos. Neste último sentido, a decisão relacionada com as condições da comunidad Endorois en Kenya, adotada pela Comissão Africana de Direitos Humanos e dos Povos, é relevante sobretudo quando afirma que o direito ao desenvolvimento implica a capacidade de eleição, isto é, a liberdade de eleição deve estar presente como parte do direito ao desenvolvimento. Entre o direito humano ao desenvolvimento e o princípio do desenvolvimento sustentável se produz uma relação virtuosa e de retroalimentação. O direito ao desenvolvimento não persegue qualquer tipo de desenvolvimento. $\mathrm{Na}$ época atual, o desenvolvimento ao qual se referiria esse direito deveria incluir componentes de sustentabilidade.

Isso tem restado claro na recente decisão da Corte Africana de Direitos Humanos e dos Povos no caso Povo Indigena Ogiek de 26 de maio de 2017 (African Commission on Human and Peoples' Rights v. Republic of Kenya, 2017). No caso do povo Ogiek, a Corte Africana de Direitos Humanos e dos Povos concretiza um diálogo entre juízes de caráter horizontal já que utiliza dentro da ratio decidendi de seu julgado critérios relevantes estabelecidos na clássica jurisprudência sobre povos indígenas da Corte IDH (Piovesan, 2014a) (Aguilar Cavallo, 2013).

Em consequência, o direito ao desenvolvimento é um direito humano que faculta participar das decisões de desenvolvimento, assim como contribuir e desfrutar desse de tal maneira que possam realizar-se plenamente todos os direitos humanos. Portanto, é da essência desse direito ao desenvolvimento a realização, com total efetividade, dos direitos humanos (Burgoa Toledo, 2013). Dessa maneira, a plena efetividade de todos os direitos humanos é, assim mesmo, conditio sine qua non para a satisfação do desenvolvimento. Nesse sentido, Piovesan (2004, p.37), citando Eide, tem sustentado corretamente que a "acción gubernamental debe promover la igualdad social, enfrentar las desigualdades sociales, compensar los desequilibrios creados por los mercados y asegurar un desarrollo humano sostenible".

O conceito de bem viver é sem dúvida uma noção vinculada com os saberes indígenas e que manifesta a necessidade do homem de viver em harmonia 
com a natureza, ainda quando não exista um conceito único de bem viver (Vanhulst, 2015). Portanto, o bem viver proporia uma forma alternativa ao desenvolvimento eurocêntrico, isso é, uma "sociedad buena para todos en suficiente armonía interna y con particular respeto a la Madre Tierra” (Tortosa, 2011, p.13). Caria e Domínguez (2014, p.144) destacam que é possível distinguir cinco elementos constitutivos comuns às diversas noções de bem viver: "armonía con la Naturaleza; reivindicación de los principios y valores de los pueblos ancestrales; satisfacción de las necesidades básicas; justicia social e igualdad como responsabilidades del Estado; y democracia". Além do mais, esses autores agregam que existem elementos transversais "el buen vivir como proyecto en construcción permanente y el buen vivir como crítica al paradigma de la modernidad de matriz occidental, antropocéntrica, capitalista y economicista" (Caria; Domínguez, 2014, p.144).

Por sua vez, Canqui Mollo (2011, p.32),

[...] postula una visión cosmocéntrica y diversidad cultural, es una expresión cultural que condensa la forma de entender la satisfacción compartida de las necesidades humanas, más allá del ámbito de lo material y económico. El Vivir Bien es también la satisfacción de la participación social, politica y económica de las personas.

Nessa linha, e resgatando os conhecimentos alternativos ao eurocentrismo, o "bem viver" se projeta "hacia un nuevo tipo de desarrollo social, politico, económico y ecológico que se distancia claramente del modelo neoliberal" (Vanhulst; Beling, 2013, p.5). Prieto Acosta (2004, p.138) tem destacado as virtudes do conhecimento indígena tradicional para o desenvolvimento sustentável, sobretudo, para a conservação e o equilíbrio ecológico, quando assinala que

[...] las comunidades indigenas pueden ofrecer a las sociedades modernas muchas lecciones en el manejo de recursos en complejos bosques, montañas y ecosistemas con sequía, y de ahi que el papel que desempeñan los indigenas en la preservación de la biodiversidad sea crucial por su habilidad para utilizar su ambiente natural.

Assim mesmo, nessa linha, Gentes (2002, p.84) refere que os valores, crenças e rituais indígenas constituem "un sistema de reglas y una ética común del uso de los recursos naturales".

Em específico, por exemplo, em relação com a gestão da água e a diversidade ambiental,

[...] la relación de los pueblos indigenas con el agua no es de simples usufructuarios, sino que juegan -en particular las comunidades forestales- un papel muy importante en la conservación de las cuencas hidrográficas. [...] En ese punto ofrecen servicios ambientales muy valiosos para la sociedad. (Peña, 2004, p.20)

A noção de "bem viver" tem sido indiretamente admitida pelos órgãos do sistema interamericano de proteção dos direitos humanos através de duas deci- 
sões e sentenças, especialmente, nos casos indígenas, onde estão envolvidas suas terras e recursos naturais.

\section{O conbecimento indigena e a jurisprudência interamericana}

O pilar jurídico fundamental para a reivindicação dos conhecimentos indígenas tradicionais é o direito à autodeterminação dos povos indígenas (Bernal Camargo, 2013). Em virtude desse direito, os povos indígenas têm a soberania permanente e, portanto, o controle sobre suas riquezas e recursos naturais. Nesse sentido, Daes tem corretamente articulado esse direito assinalando que "se trata de un derecho colectivo en virtud del cual los Estados están obligados a respetar, proteger y promover los intereses de gobierno y de propiedad de los pueblos indigenas (como colectividades) sobre sus recursos naturales" (Comisión de Derechos Humanos, 2004, par.56).

É evidente que o reconhecimento dos direitos coletivos dos povos indígenas, o qual implica o reconhecimento de sua cultura, de seus usos, costumes e visões do mundo, enfim, de seu conhecimento indígena tradicional, é extremamente relevante para sua própria sobrevivência e para seu próprio desenvolvimento sustentável (ibidem, par.55). Com efeito, a CIDH, seguindo a jurisprudência da Corte IDH, vem afirmando que

[...] [l]os Estados deben tener en cuenta que la cultura de los miembros de las comunidades indigenas corresponde a una forma de vida particular de ser, ver y actuar en el mundo, constituido a partir de su estrecha relación con sus territorios tradicionales y los recursos que alli se encuentran, no sólo por ser éstos su principal medio de subsistencia, sino además porque constituyen un elemento integrante de su cosmovisión, religiosidad $y$, por ende, de su identidad cultural. (CIDH, 2009, par.182) ${ }^{2}$

A principal ideia que se trata de veicular neste trabalho é que o conhecimento indígena tradicional, acumulado através dos séculos especialmente em matéria de conservação da biodiversidade e uso sustentável dos recursos naturais, pode converter-se em um sistema de conhecimento alternativo, igualmente valioso para alcançar os objetivos intrínsecos que traduzem o desenvolvimento sustentável. Por ora, o sistema interamericano tem dado um primeiro passo, abrindo a porta à constatação desse tipo de conhecimento local indígena, rico em experiências e explicações relacionadas com o meio ambiente em que vivem (Nakashima; Prott; Bridgewater, 2000). Como observamos anteriormente, uma das possíveis manifestações desses conhecimentos indígenas tradicionais se encontra na noção de "bem viver".

Nesse contexto, a CIDH (2009, par.181) tem afirmado o seguinte:

[...] la jurisprudencia del sistema interamericano de derechos humanos sobre el derecho de propiedad comunal de los pueblos indigenas ha incorporado explicitamente en el ámbito material de este derecho los recursos naturales tradicionalmente usados por los pueblos indigenas y vinculados a sus culturas, incluyendo usos tanto estrictamente materiales como otros usos de carácter espiritual o cultural. 
Desse modo, a cosmovisão indígena a propósito de terras e recursos naturais resta revelada com a seguinte passagem da sentença da Corte IDH no caso dos povos Kaliña e Lokono, de 2015, ao destacar:

Para ellos, todos los animales, plantas, peces, piedras, arroyos y ríos son seres vivos interconectados entre si que cuentan con espiritus protectores. Sobre esta relación espiritual, se destaca que con motivo de su cosmovisión, los propios indigenas restringen el ingreso a ciertos territorios, la tala de determinados árboles, como los takini, kumaka, uremari y kwasini, y la captura o caza de algunos animales y peces, como las boas constrictoras, manaties, delfines y tortugas. Además, cuentan con dos reglas generales que guian el uso y extracción de recursos naturales, a saber: i) no cazar o talar especimenes jóvenes, y ii) usar únicamente lo que se necesita. [...] Asimismo, los Pueblos Kaliña y Lokono cuidan sus tierras no solo porque ellos y sus futuras generaciones necesitan un lugar donde vivir, sino que la cultura y costumbres que les han inculcado sus ancestros se fundamentan en un profundo respeto por el medioambiente, que incluye tanto los seres vivos como los objetos inanimados. (Corte IDH, 2015 c, par.33)

Como se pode observar, a noção de bem viver se encontra implicitamente presente na jurisprudência interamericana. No sistema interamericano de proteção dos direitos humanos, a conexão e inter-relação entre direitos humanos, proteção do meio ambiente e desenvolvimentos sustentável se tem produzido, portanto, primeiramente, em razão dos casos de direitos coletivos dos povos indígenas (Corte IDH, Opinión Consultiva, 2016, par.74). Nos casos sobre povos indígenas e a propósito da proteção do meio ambiente e do uso dos recursos naturais, a noção de bem viver ocupa um lugar preponderante.

No caso dos povos Kaliña e Lokono de 2015, a Corte IDH reitera sua jurisprudência constante no que diz respeito ao reconhecimento e proteção sob o direito a propriedade, das formas tradicionais de exercício do direito ao uso e gozo de seus recursos naturais. Desconhecer essa proteção seria discriminatório e atentaria contra sua própria sobrevivência física e cultural. Inclusive, a Corte realiza implicitamente a conexão entre o especial modo holístico de relacionar-se com a terra e seus recursos naturais que detêm os povos indígenas e o desenvolvimento sustentável, já que os juízes interamericanos reconhecem a intenção desses povos de preservar seu legado cultural e transmiti-lo às gerações futuras. Com efeito,

[E]ntre los pueblos indigenas existe una tradición comunitaria sobre la propiedad colectiva de la tierra, en el sentido de que la pertenencia a ésta no se centra en un individuo sino en el grupo y su comunidad. [...] Desconocer las versiones especificas del ejercicio del derecho al uso y goce de los bienes, dadas por la cultura, usos, costumbres y creencias de cada pueblo, equivaldría a sostener que solamente existe una forma de usar y disponer de los bienes, lo que a su vez significaria hacer ilusoria la protección de tal disposición para estos colectivos. (Corte IDH, 2015c, par.129) 
Especialmente a respeito dos recursos naturais que os povos indígenas tradicionalmente têm possuído ou usado de outra forma, a Corte IDH $(2015 \mathrm{c}$, par.164) tem sustentando que "los pueblos indigenas tienen el derecho de ser titulares de los recursos naturales que han usado tradicionalmente dentro de su territorio, ya que sin ellos su supervivencia económica, social y cultural está en riesgo". Do mesmo modo, nesse sentido, uma referência obrigatória constitui o conhecido caso da Comunidade Indigena Yakye Axa vs. Paraguay de 2005.

Nos casos sobre terras e territórios indígenas, a Corte IDH tem desenvolvido ainda mais a proteção do meio ambiente e desenvolvimento sustentável. ${ }^{3}$ Assim, a Corte IDH refere a obrigação de se realizar um estudo de impacto ambiental e, como contrapartida, o direito a que esse se realize. Os critérios que estabelecem seriam os seguintes: a) Não se pode iniciar nenhum projeto de investimento ou desenvolvimento enquanto não haja um Estudo de Impacto Ambiental e Sociais (EIAS); b) O EIAS deve ser realizado por entidades independentes e tecnicamente capazes; c) O EIAS deve ser devidamente supervisado pelo Estado; e d) O Estudo deve incluir o aspecto social, cultural, espiritual e a afetação de direitos humanos.

A obrigação em realizar um estudo prévio de impacto social e ambiental e acrescentaríamos o impacto nos direitos humanos - aparece aqui aprimorada como um eventual instrumento que poderia refletir uma doutrina constitucional que se situa no caminho da solidariedade, do dever e da responsabilidade.

\section{Conclusão}

A riqueza da biodiversidade e o enorme valor ambiental dos recursos existentes nas terras e territórios indígenas são cobiçados pelos Estado e pelos atores privados com a desculpa do desenvolvimento, e, portanto, se encontram em perigo real, recordando-nos uma colonização inacabada. O perigo não é somente para os direitos coletivos dos povos e comunidades indígenas às suas terras e recursos naturais, que têm sido conservados e usados sustentavelmente durante séculos, mas sim um risco real para a própria sobrevivência humana.

Os conhecimentos alternativos indígenas e saberes tradicionais constituem um patrimônio valioso que pode nos proporcionar uma via alternativa à visão hegemônica imposta de desenvolvimento e de crescimento econômico unicamente baseado na exploração e extração incessante dos recursos, efetuados quase sempre em nome de um número cada vez mais crescente de liberdades econômicas sem consideração à conservação ambiental e ao equilíbrio ecológico. Desde o conhecimento indígena se nos apresenta a noção de bem viver como uma via alternativa de desenvolvimento em harmonia com o meio ambiente, considerando a dignidade da natureza através do ser humano.

A Corte IDH tem dado passos concretos no sentido de ir construindo uma base jurídica para a aceitação desses conhecimentos alternativos em relação com as terras, os territórios e os recursos naturais indígenas. No interior dos Estados, na América, sobressaem-se exemplos constitucionais do Equador e da 
Bolívia. Resta saber se essa via será abraçada por ainda mais países do continente e, também, como uma alternativa planetária que nos permita traçar um caminho para um novo desenvolvimento que nos assegura um "bem viver” global.

\section{Notas}

1 A Declaração Universal dos Direitos Humanos reconhece como base "a dignidade intrínseca" de todos os membros da família humana.

2 Caso Comunidad Indigena Yakye Axa vs. Paraguay (Corte IDH, 2005, par.135).

3 Ver, nesse sentido: Caso Pueblo Indigena Kichwa de Sarayaku vs. Ecuador (Corte IDH, 2012, par.205); Caso del Pueblo Saramaka vs. Surinam (Corte IDH, 2007, par.130).

\section{Referências}

ACOSTA, A. .El buen vivir, una utopía por (re)construir. In: DEL VISO, N. (Coord.) Enfoques sobre bienestar y buen vivir. Fuhem: Madrid, 2010. p.11-28.

El buen vivir como alternativa al desarrollo. Algunas consideraciones económicas y no tan económicas. Política y Sociedad, v.52, n.2, p.299-330, 2015.

AGUILAR CAVALLO, G. El diálogo judicial multinivel. In: NOGUEIRA ALCALÁ, H. (Coord.) Diálogo judicial multinivel y principios interpretativos favor persona $y$ de proporcionalidad. Santiago de Chile: Librotecnia, 2013. p.55-102.

Las fuentes y el alcance del derecho al desarrollo y su indivisibilidad con el derecho a vivir en un medio ambiente libre de contaminación. Revista Ius et Praxis, año 23, n.l, p.465-508, 2017.

ALONSO HIERRO, J.; MARTÍN FERNÁNDEZ, J. Activos culturales y desarrollo sostenible: la importancia económica del patrimonio cultural. Politica y Sociedad, v.50, n.3, p.1133-47, 2013.

BARRAGÁN ALVARADO, L. Gestión de áreas protegidas en territorios indígenas. Revista Parques, n.2, 2011. Disponível em: <http://revistaparques.net/uploads/media/ art44.pdf>. Acesso: dez. 2017.

BERKES, F.; FOLKE, C.; GADGIL, M. Traditional Ecological Knowledge, Biodiversity, Resilience and Sustainability. In: PERRINGS C.A. et al. (Ed.) Biodiversity Conservation. Dordrech: Kluwer, 1995. p.281-299.

BERKES, F.; COLDING, J.; FOLKE, C. Rediscovery of traditional ecological knowledge as adaptive management. Ecological Applications, v.10, n.5, p.1251-62, 2000.

BERNAL CAMARGO, D. R. Protección de los recursos genéticos de los pueblos indígenas en los sistemas universal e interamericano de derechos humanos. Boletín Mexicano de Derecho Comparado, año XLVI, n.138, p.909-37, 2013.

BOCO, R.; BULANIKIAN, G. Derechos humanos: universalismo vs. relativismo cultural. Alteridades, v.20, n.40, p.9-22, 2010.

BOSSELMANN, K. The principle of sustainability. Transforming law and governance. Farnham; Burlington: Ashgate Pub, 2008. p.120-1. 
BURGOA TOLEDO, C. A. La efectividad de los derechos humanos y sus garantías. Universos Jurídicos. Revista de Derecho Público y Diálogo Multidisciplinar, año 1, n.1, p.173-97, 2013.

CABA, S.; GARCÍA, G. La denuncia al eurocentrismo en el pensamiento social latinoamericano y la problemática de la universalidad del conocimiento. Polis. Revista Latinoamericana, n.38, p.1-18, 2014.

CANQUI MOLLO, E. El vivir bien, una propuesta de los pueblos indígenas a la discusión sobre el desarrollo. Obets. Revista de Ciencias Sociales, v.6, n.1, p.19-33, 2011.

CARIA, S.; DOMÍNGUEZ, R. El porvenir de una ilusión: la ideología del buen vivir. América Latina Hoy, n.67, p.139-63, 2014.

CASTRO-GÓMEZ, S.; GROSFOGUEL, R. Giro decolonial, teoría crítica y pensamiento heterárquico. In: CASTRO-GÓMEZ, S.; GROSFOGUEL, R. (Ed.) El giro decolonial. Reflexiones para una diversidad epistémica más allá del capitalismo global. Bogotá: Siglo del Hombre Editores, 2007. p.9-23.

CIDH. Derechos de los Pueblos Indigenas y Tribales sobre sus tierras ancestrales y recursos naturales. Normas y Jurisprudencia del Sistema Interamericano de Derechos Humanos. Cap. VIII. Doc. OEA/Ser.L/V/II., Doc. 56/09, 30 diciembre 2009.

COMISIÓN DE DERECHOS HUMANOS. Estudio sobre la protección de la propiedad cultural e intelectual de los pueblos indigenas preparado por la Sra. Erica-Irene Daes, Relatora Especial de la Subcomisión de Prevención de Discriminaciones y Protección a las Minorias y Presidenta del Grupo de Trabajo sobre Poblaciones Indigenas. Doc. N.U. E/ CN.4/Sub.2/1993/28, de fecha 28 de julio de 1993.

Informe del seminario sobre el proyecto de principios y directrices para la protección del patrimonio de los pueblos indigenas. (Ginebra, 28 de febrero a $1^{\circ}$ de marzo de 2000) Presidenta-Relatora: Sra. Erica-Irene A. Daes. Doc. N.U. E/CN.4/ Sub.2/2000/26, de fecha 19 de junio de 2000.

. La soberania permanente de los pueblos indigenas sobre sus recursos naturales. Informe final de la Relatora Especial Sra. Erica-Irene A. Daes. Doc. N.U. E/CN.4/ Sub.2/2004/30, de fecha 13 de julio de 2004.

COMISIÓN MUNDIAL SOBRE EL MEDIO AMBIENTE Y EL DESARROLLO (CMMAD): Nuestro Futuro Común. Doc. N.U. A/42/427, de fecha 4 de agosto de 1987.

CORREA MUÑOZ, M. E.; SALDARRIAGA GRISALES, D. C. El epistemicidio indígena latinoamericano. Algunas reflexiones desde el pensamiento crítico decolonial. Revista CES DERECHO, v.5, n.2, p.154-64, 2014.

CORTE IDH. Caso Bámaca Velásquez vs. Guatemala. Fondo. Sentencia de 25 de noviembre de 2000. Serie C No. 70. Voto razonado del juez A. A. Cançado Trindade. Disponível em: <http://www.corteidh.or.cr/>. Acesso em: 20 jul. 2018.

Caso Comunidad Indigena Yakye Axa vs. Paraguay. Fondo Reparaciones y Costas. Sentencia 17 de junio de 2005. Disponível em: <http://www.corteidh.or.cr/>. Acesso em: 20 jul. 2018.

CORTE IDH. Caso del Pueblo Saramaka vs. Surinam. Excepciones Preliminares, Fondo, Reparaciones y Costas. Sentencia de 28 de noviembre de 2007. Disponível em: <http://www.corteidh.or.cr/>. Acesso em: 20 jul. 2018. 
CORTE IDH. Caso Pueblo Indigena Kichwa de Sarayaku vs. Ecuador. Fondo y reparaciones. Sentencia de 27 de junio de 2012. Disponível em: <http://www.corteidh. or.cr/>. Acesso em: 20 jul. 2018.

Caso Gonzales Lluy y otros vs. Ecuador. Excepciones Preliminares, Fondo, Reparaciones y Costas. Sentencia de 1 de septiembre de 2015a. Disponível em: <http:// www.corteidh.or.cr/>. Acesso em: 20 jul. 2018.

Caso Comunidad Garifuna Triunfo de la Cruz y sus miembros vs. Honduras. Fondo, Reparaciones y Costas. Sentencia de 8 de octubre de 2015b. Disponível em: <http://www.corteidh.or.cr/>. Acesso em: 20 jul. 2018.

Caso Pueblos Kaliña y Lokono vs. Surinam. Fondo, Reparaciones y Costas. Sentencia de 25 de noviembre de 2015c. Disponível em: <http://www.corteidh.or.cr/>. Acesso em: 20 jul. 2018.

Titularidad de derechos de las personas juridicas en el sistema interamericano de derechos humanos (Interpretación y alcance del articulo 1.2, en relación con los articulos 1.1, 8, 11.2, 13, 16, 21, 24, 25, 29, 30, 44, 46, y 62.3 de la Convención Americana sobre Derechos Humanos, asi como del artículo 8.1 A y B del Protocolo de San Salvador). Opinión Consultiva OC-22/16 de 26 de febrero de 2016.

DECLARACIÓN VIENA+20 OSC, adoptada en Viena el 26 de junio de 2013.

ESTENSSORO, F. El ecodesarrollo como concepto precursor del desarrollo sustentable y su influencia en América Latina. Universum, v.30, n.1, p.81-99, 2015.

ESTERMANN, J. Crisis civilizatoria y vivir bien. Polis. Revista Latinoamericana, n.33, p.1-22, 2012.

EUDAVE EUSEBIO, I. Invención, colonización y memoria indígena en la narrativa de Fray Bernardino de Sahagún. Diálogo Andino, n.49, p.57-72, 2016.

FERRERO HERNÁNDEZ, R. Protección de la propiedad comunal indígena por la Corte Interamericana. Revista del Instituto Interamericano de Derechos Humanos, v.63, p.65-103, 2016.

FLORES RENTERÍA, J. Justicia y derechos humanos. Politica y Cultura, n.35, p.27$45,2011$.

FRIAS, E. El aporte de los indígenas al ambiente se revaloriza. El Comercio. Disponível em: <http://www.elcomercio.com/tendencias/aporte-indigenas-ambiente-intercultural-cambioclimatico.html>. Acesso em: 17 jan. 2017.

GAREIS, I. Identidades latinoamericanas frente al colonialismo - una apreciación histórico-antropológica. Indiana, v.22, p.9-18, 2005.

GENTES, I. Derecho de agua y derecho indígena. Hacia un reconocimiento estructural de la gestión indígena del agua en las legislaciones nacionales de los Países Andinos. Revista de Derecho Administrativo Económico, n.1, p.81-111, 2002.

GÓMEZ ISA, F. Diversidad cultural y derechos humanos desde los referentes cosmovisionales de los pueblos indígenas. Anuario Español de Derecho Internacional, v.27, p.267-313, 2011

GROS ESPIELL, H. Reflexiones en torno a la protección internacional de los derechos humanos en el ámbito regional americano. Cursos de Derecho Internacional de Vitoria-Gasteiz, n.1, p.165-86, 1987. 
HOUTART, F. El concepto de sumakkawsai (buen vivir) y su correspondencia con el bien común de la humanidad. ALAI, América Latina en Movimiento, 2011. Disponível em: <http://www.dhl.hegoa.ehu.es/ficheros/0000/0738/15._El_concepto_de_sumak_kawsai.pdf>. Acesso em: 2 dez. 2017.

INFORME de la Comisión Verdad Histórica y Nuevo Trato con los Pueblos Indígenas. Editado por el Comisionado Presidencial para Asuntos Indígenas. Primera edición, Santiago de Chile, octubre de 2008.

JARIA I MANZANO, J. El constitucionalismo de la escasez (derechos, justicia y sostenibilidad). Revista Aranzadi de Derecho Ambiental, n.30, p.295-349, 2015.

MARTÍNEZ CASTILLO, R. Biopiratería y pueblos indígenas: crítica y realidad. Revista Latinoamericana de Derechos Humanos, v.20, n.1, p.27-38, 2009.

MARTÍNEZ DE BRINGAS, A. Las políticas interculturales ante el reto de los derechos de los pueblos indígenas, 2009, p.4. Disponível em: <http://www.proyectos.cchs.csic. es/interjust/sites/proyectos.cchs.csic.es.interjust/files/Las_politicas_multiculturales_ante_el_reto_de_los_derechos_de_los_pueblos_indigenas.pdf>. Acesso em: 3 dez. 2017.

MEJÍA NAVARRETE, J. Modernidad y conocimiento social. La emergencia de un discurso epistémico en American Latina. Cinta de Moebio, Revista de Epistemología de Ciencias Sociales, n.54, p.290-301, 2015.

METZ, T. Ubuntu as a Moral Theory and Human Rights in South Africa. African Human Rights Law Journal, v.11, p.532-59, 2011.

MURRAY LI, T. La limpieza étnica, los conocimientos recursivos y los dilemas del sedentarismo. Revista Internacional de Ciencias Sociales, n.173, p.361-71, 2002.

NAKASHIMA, D.; PROTT, L.; BRIDGEWATER, P. Tapping into the World's Wisdom. Sources, n.125, 2000.

OMPI. Mesa redonda sobre la propiedad intelectual y los conocimientos tradicionales. Ginebra, 1 y 2 de noviembre de 1999. Doc. OMPI/IPTK/RT/99/3, de fecha 6 de octubre de 1999.

Conocimientos tradicionales: necesidades y expectativas en materia de propiedad intelectual. Informe relativo a las misiones exploratorias sobre propiedad intelectual y conocimientos tradicionales (1998-1999). Ginebra, 2001.

PAECH, N. Die Postwachstumsökonomie - ein Vademecum. Zeitschrift für Sozialökonomie (ZfSÖ), v.46/160-161, p.28-31, 2009.

PEÑA, F. Pueblos indígenas y manejo de recursos hídricos en México. Revista Mad, n.11, p.20-9, 2004.

PÉREZ PINO, V. Educación ambiental y cosmovisión de los pueblos originarios, Conama, Región de Tarapacá, 2017. Disponível em: <http://www.ceh.cl/GEFSDH2010/ GEFpdf/Seminarios/fo-article-29181.pdf>.

PINHEIRO, P. S.; EL-CHICHINI POPPOVIC, M.; KAHN, T. Pobreza, violencia e direitos humanos. Novos Estudos, n.39, p.189-208, 1994.

PIOVESAN, F. Derechos sociales, económicos y culturales y derechos civiles y políticos. Sur - Revista Internacional de Derechos Humanos, año 1, n.1, p.21-47, 2004. Proteção dos direitos sociais: desafios do ius commune sul-americano. Revis- 
ta de Estudos Constitucionais, Hermeneutica e Teoría do Direito (RCHTD), v.3, n.2, p.206-26, 2014a.

Sistema Interamericano de Direitos Humanos: impacto transformador, diálogos jurisdicionais e os desafios da reforma. Revista de Estudos Constitucionais, Hermenêutica e Teoria do Direito (RECHTD), v.6, n.2, p.142-54, 2014 b.

PNUD. Informe sobre desarrollo humano 2015. Trabajo al servicio del desarrollo humano. Nova York: PNUD, 2015.

PNUD: Informe sobre desarrollo humano 2011. Sostenibilidad y Equidad: Un mejor futuro para todos. PNUD, Nueva York, 2011.

PRIETO ACOSTA, M. Conocimiento indígena tradicional: el verdadero guardián del oro verde. Boletín de Antropología, v.18, n.35, p.132-64, 2004.

QUIJANO, A. "Bien vivir": entre el "desarrollo" y la des/colonialidad del poder. Viento Sur, n.122, p.46-56, 2012.

SOUSA SANTOS, B. de. Pensar el Estado y la sociedad: desafíos actuales. Buenos Aires: Waldhuter, 2009.

- Descolonizar el saber, reinventar el poder. Montevideo: Trilce, 2010.

$39,2011$.

. Epistemologías del Sur. Utopía y Praxis Latinoamericana, año 16, n.54, p.17-

TORTOSA, J. M. Vivir bien, buen vivir: caminar con los dos pies. Obets. Revista de Ciencias Sociales, v.6, n.1, p.13-17, 2011.

TRESIERRA, J. C. Derechos de uso de los recursos naturales por los grupos indigenas en el bosque tropical. Banco Interamericano de Desarrollo, Washington, p.28-29, 2000.

VANHULST, J. El laberinto de los discursos del Buen vivir: entre Sumak Kawsay y Socialismo del siglo XXI. Polis. Revista Latinoamericana, v.14, n.40, p.233-61, 2015.

VANHULST, J.; BELING, A. E. Buen vivir: la irrupción de América Latina en el campo gravitacional del desarrollo sostenible. Revista Iberoamericana de Economía Ecológica, v.21, p.1-14, 2013.

VELASCO CRIADO, D. Los antecedentes histórico-ideológicos de la Declaración Universal de los Derechos del Hombre de 1948. In: LA DECLARACIÓN Universal de los Derechos Humano en su cincuenta aniversario: un estudio interdisciplinar. Universidad de Deusto-Instituto de Derechos Humanos Pedro Arrupe, Bilbao, 1999.

RESUMO - Este trabalho pretende ressaltar o conhecimento indígena tradicional ante o conhecimento eurocentrista em matéria de preservação da natureza e do patrimônio ambiental. Ante a atual crise ambiental, o resgate do conhecimento ecológico indígena aparece como uma alternativa para o desenvolvimento diante das ineficazes fórmulas de acumulação, vestígios do colonialismo. O sistema interamericano de proteção de direitos humanos tem contribuído com um reconhecimento dos direitos coletivos dos povos indígenas sobre suas terras e recursos naturais. Esse reconhecimento contém em si mesmo a aceitação dos conhecimentos ecológicos indígenas, os quais poderão contribuir para o estabelecimento de um novo modelo de desenvolvimento. 
PALAVRAS-CHAVES: Conhecimentos ecológicos tradicionais, Descolonização, Povos indígenas, Recursos naturais, Direitos humanos.

ABSTRACT - This paper aims to highlight traditional indigenous knowledge vis-à-vis Eurocentric knowledge regarding the conservation of nature and the preservation of the environmental heritage. Considering the environmental crisis, the validation of indigenous ecological knowledge appears to be an alternative to development in face of the ineffective recipe of accumulation of goods and other vestiges of colonialism. The Inter-American System of Human Rights has recognized the collective rights of indigenous peoples on their land and natural resources. This recognition contains in itself an acceptance of the indigenous ecological knowledge, which could contribute to a new development model.

KEYWORDS: Traditional ecological knowledge, Decolonization, Indigenous peoples, Natural resources, Human rights.

Gonzalo Aguilar Cavallo é professor da Faculdade de Direito da Universidad de Talca (Chile), e diretor do Magíster en Derecho Constitucional do Centro de Estudios Constitucionales de Chile (Cecoch). @-gaguilar@utalca.cl

Tradução de Maria Valentina de Moraes. O original em espanhol - "Conocimientos ecológicos indígenas y recursos naturales: la descolonización inacabada" - encontra-se à disposição do leitor no Instituto de Estudos Avançados da USP para eventual consulta.

Recebido em 18.9.2018 e aceito em 22.10.2018.

${ }^{\text {I }}$ Faculdade de Direito, Universidad de Talca, Talca, Chile. 